\title{
RELATIONSHIP BETWEEN DEBRIS WITHIN GRAPE BUNCHES AND BOTRYTIS INFECTION OF BERRIES
}

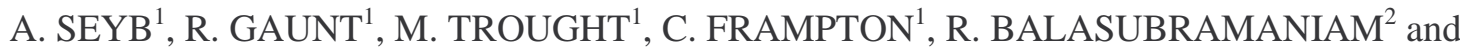 \\ M. JASPERS ${ }^{1}$ \\ ${ }^{1}$ PO Box 84, Lincoln University, Canterbury, New Zealand \\ ${ }^{2}$ HortResearch, Marlborough, New Zealand
}

The relationship between necrotic grape tissue found trapped within bunches (bunch trash) and Botrytis cinerea infection of berries was assessed at harvest in three Marlborough Sauvignon blanc vineyard blocks, during three growing seasons from 1998 to 2000. There were differences $(\mathrm{P}<0.01)$ in the amount of trash components/bunch. The percent infestation also differed between tissues $(\mathrm{P}<0.01)$, with stamens $(0)$, aborted flowers (10, 4 and 8), aborted berries (30, 20 and 14), calyptras $(35,15$ and 10), damaged mature berries (50, 44 and 52), tendrils $(73,32$ and 77$)$ and leaf pieces (47, 32 and 41) in 1998, 1999 and 2000 respectively. Aborted and damaged berries and calyptras are the components most likely to provide inoculum for bunch rot because they are both relatively numerous and commonly infested. These components of bunch trash were positively correlated with the presence of infected berries at harvest in some vineyards in some seasons. The reasons for variations in rate of infestation are discussed.

\section{PLANT PEST INFORMATION NETWORK (PPIN): AN ACTIVE INFORMATION SYSTEM TO SUPPORT YOUR RESEARCH}

\author{
K.L. BEAL \\ National Plant Pest Reference Laboratory, Ministry of Agriculture and Forestry, PO Box 24, Gerald \\ Street, Lincoln, New Zealand
}

Surveillance information is the cornerstone of New Zealand's agricultural security and market access. Knowledge of our pest and disease status enables the development of quarantine specifications, and supports negotiations with trading partners. The Plant Pest Information Network (PPIN, pronounced 'pippin') is a national database maintained by the National Plant Pest Reference Laboratory (NPPRL), for the collection, collation, management and dissemination of plant pest surveillance information. It holds records of pest/organism occurrence (including fungi, bacteria, viruses, nematodes and insects), their hosts and distribution. The records which are reported to the Director Plants Biosecurity and Director Forest Biosecurity of MAF Biosecurity Authority include organisms new to New Zealand, new pest-host associations and new pest distributions. PPIN holds approximately 22,000 records related to significant horticultural/agricultural crops. Other crops, including those of forestry interest, will be included as information is reported or becomes available. Support and input from the scientific community is necessary to build and maintain an accurate, upto-date set of surveillance data. New or unpublished records can be forwarded to the PPIN Administrator. In addition, allied organisations (i.e. research institutes, museums and universities) and the public are able to request information from the database. 